\title{
O EVENTO HUMANO: A OBLITERAÇÃO DO PROCESSO HOMINIZANTE EM SCHELER
}

\author{
THE HUMAN EVENT: THE OBLITERATION OF HOMINIZATION PROCESS IN SCHELER
}

Denis de Souza Azevedo*

\begin{abstract}
RESUMO
O filósofo alemão Max Scheler elabora seu pensamento na tentativa de formular um conceito de "homem" com o qual possa aprofundar sua espiritualidade. Em outros termos, Scheler quer dar ao homem o estatuto de relação primária com Deus. Sendo assim, este pensador, com a pretensão de fazer uma antropologia filosófica, acaba caindo em uma espécie de teologia antropológica, uma vez que o homem é um centro espiritual. O espírito, por sua vez, foge às "intempéries" do mundo orgânico, tornando o homem um asceta da vida. Dessa forma, a antropologia filosófica de Scheler é uma tentativa de definir o homem como um movimento em busca da sua própria divinização. Esta filosofia, que ora se pretende antropológica, ora espiritual, não leva a cabo a tarefa de explicar a hominização. O processo hominizante é obscurecido pela "positivação" de uma forma humana ou de uma forma animal já estabelecidas. Em outras palavras, Scheler trata o animal como um centro biológico aqui-eagora e o homem como um ser espiritual, sem demonstrar a superação, pelo homem, da animalidade requerida por uma antropologia. Isso exposto, nosso artigo tem o objetivo de mostrar a negligência scheleriana quanto a uma antropologia filosófica frente a uma filosofia espiritualista. Para tal superação, focaremos na fenomenologia merleau-pontyana e do filósofo Étienne Bimbenet.
\end{abstract}

PALAVRAS-CHAVE: Espiritualismo. Scheler. Antropologia filosófica. Merleau-Ponty. Bimbenet.

\begin{abstract}
The German philosopher Max Scheler prepares its thinking in trying to formulate a concept of "man" with which to deepen their spirituality. In other words, Scheler wants to give man the status of primary relationship with God. Thus, this thinker, with the intention of making a philosophical anthropology, ends up falling into a anthropological theology, since man is a spiritual center. The spirit, in turn, runs of the "troubles" of the organic world, making the man an ascetic of life. The philosophical anthropology of Scheler is an attempt to define man as a movement in search of his own deification. This philosophy, which now is to be anthropological, sometimes intended spiritual, does not carry out the task of explaining the humanization. The humanizing process is obscured by "positivation" of a human form or an animal form established. In other words, Scheler treats the animal as a biological center hereand-now and the man as a spiritual being without showing an overcoming by the man of animality required by anthropology. This exposed, our paper aims to show schelerian neglect of a philosophical anthropology front of a spiritualist philosophy. To overcome this, we will focus on merleau-pontyan phenomenology and of the philosopher Étienne Bimbenet.
\end{abstract}

KEYWORDS: Spiritualism. Scheler. Philosophical anthropology. Merleau-Ponty. Bimbenet.

\footnotetext{
* Mestre em Filosofia pela Universidade Federal da Paraíba. E-mail: souza.denisde@gmail.com
} 


\section{Introdução}

O filósofo alemão Max Scheler (1874-1928), principalmente em sua obra A Posição do Homem no Cosmos (1928/2003), traça um panorama de uma antropologia filosófica. Esta empreitada inicia-se, gradualmente, com a diferenciação entre os seres vivos. O caminho percorrido parte do impulso afetivo das plantas, passando pelo instinto animal, a memória e a inteligência. Estes três últimos remetem-se unicamente ao animal e ao homem, com diferenças precisas e com a posse do espírito pelo ser humano.

Para Scheler (2003, p. 8) é certo que os seres vivos possuem tanto a característica de serem objetos para outros como uma dimensão de ser-para-si e um ser íntimo. À primeira característica podemos atribuir o mecanismo de sobrevivência, mecanismo tal que busca no mundo o sustento da manutenção de sua vida. Seu ser íntimo refere-se à sua "essência" enquanto tal, isto é, àquilo que o determina enquanto um ser vivo específico que o diferencia de outras espécies, não apenas por sua constituição biológica, mas com as particularidades da inteligência, da consciência, dentre outros determinantes que veremos no decorrer do trabalho.

O impulso para o crescimento e reprodução, estritamente referente às plantas, é um impulso vital ekstático, ou seja, remete-se ao que Scheler denominou de ser-para-si: vinculase apenas a buscar no mundo o que é preciso para manter a vida. Na planta, portanto, podemos ver uma grande falta quando a comparamos com o animal ou com o homem. Esta falta é a junção da inexistência de: i) locomoção espontânea; ii) caráter informacional que permite a convivência entre a mesma espécie a partir de certo modo de vida, e, também, sua "independência" frente à presença das coisas em seu meio; iii) referência de estados orgânicos a um centro próprio, como no caso dos animais e do homem; etc.

Diferentemente, no animal, segundo Scheler (2003, p. 15), o instinto vem seguir a este impulso da planta que expusemos. O instinto refere-se ao comportamento (behavior) animal. O comportamento e, por conseguinte, o instinto não se remetem às unidades fisiológicas básicas de sustentação do ser vivo, mas ao advento de efeitos físico-químicos para a sua caracterização. O instinto, portanto, tem importante significação para a vida da espécie, alertando o organismo para diferentes situações. Ele torna o comportamento uma habilidade própria do animal, isto é, aperfeiçoa-se e especializa-se através de experiência e aprendizado, como nos casos dos animais de caça (SCHELER, 2003, p. 17). Em adição ao instinto, podemos perceber nos animais uma certa inteligência prática. Scheler (2003, p. 29) defende a 
inteligência como "astuta" ou "estulta". A primeira significa uma inteligência que visa sua meta final por meio de situações novas, atípicas da espécie. Podemos ver isso, hoje, claramente, nas experiências feitas com corvos da Nova Caledônia, realizadas por cientistas da Universidade de Auckland, na Nova Zelândia, aves tais que fizeram ganchos para "pescar" a comida em um depósito. A inteligência estulta, ou seja, aquela que não atinge, em verdade, sua meta, é, ainda assim, uma inteligência prática, tendo em vista que ela é sempre um agir, seja alcançando, seja perdendo seu fim.

Tendo exposto essas distinções básicas, Scheler parte para a explicação da construção do mundo psíquico, enfatizando a diferença essencial entre o homem e o animal. Nesta diferenciação, o filósofo alemão lança mão do espírito como cisão fundamental entre estes dois seres. É a esta ruptura que nos focaremos neste artigo. O processo desta fenda radical entre um e outro não é narrado por Scheler. Ou ele deveria adotar o evolucionismo como narrativa de superação da animalidade ou, se não o adotasse, deveria mostrar quando e por que se inicia a espiritualização humana. Porém, não encontramos nenhuma das duas hipóteses em A Posição do Homem no Cosmos, sua principal obra antropológica. Apenas encontramos, em vez de uma antropogênese, descrições distintivas planta-animal-homem.

Para tal exercício, nos deteremos nas análises das obras de Merleau-Ponty e de Étienne Bimbenet, para podermos defender a necessidade de exposição da transição da animalidade para a humanidade. Contudo, não trataremos da vida vegetal, da qual, metodologicamente, partiu Scheler. Nossa proposta será expor a insuficiência da antropologia scheleriana a fim de mostrar o processo hominizante, processo tal que é sucumbido diante de uma passagem abrupta do animal ao homem, segundo o filósofo alemão. É preciso demonstrar o surgimento da essencialidade humana. O "aparecimento" repentino do homem, presente em Scheler, nos deixa sem norte para a narrativa de uma hominização. Em suma, é nesta negligência que nos debruçaremos. Não narraremos, neste momento, o minucioso processo que fez sairmos da animalidade para a humanidade.

\section{0 modo-de-ser da animalidade}

O método fenomenológico nos leva a um impasse quando nos propomos a analisar a experiência própria de um animal, ou seja, quando tentamos falar de como é ser um animal, viver como tal nas suas afecções e percepções. É certo que uma fala em primeira pessoa, neste caso, torna-se, à primeira vista, embaraçosa. É comum ver nosso discurso sobre o modo de ser 
dos animais já impregnado de um antropomorfismo. O que isso quer dizer? Quando nos referimos ao comportamento animal, comumente atribuímos a ele nossa perspectiva, isto é, falamos de uma espontaneidade, que nos é intrinsecamente estrangeira, a partir de nosso próprio modo de viver e de nosso próprio modo de se relacionar. Portanto, querer dar ao animal um certo estatuto humano - ou melhor, enredá-lo numa conduta contaminada por nossa experiência - é antropomorfizá-lo.

Para adentrarmos neste método fenomenológico para o processo de hominização, precisamos esclarecer as referências de mundo que encontramos tanto em Scheler como em Bimbenet. Mais limitado que o homem, o animal é pobre de mundo, isto é, ele se relaciona com aquilo que é imediatamente dado. Sua relação com as coisas são relações práticas e que se referem ao "aqui-e-agora". Portanto, para Scheler (2003, p. 37), o animal age no limite perceptivo de seu ambiente. Para Bimbenet (2014, p. 103), bebendo das fontes de Heidegger e Uexküll, o animal vive no seu meio geográfico (Umgebung), investindo aquilo visado de um sinal vital (Merkmal). Em outros termos, o animal investe de uma significação vital o que está à sua frente, para, daí, recolher sua utilidade imediata e prática. $\mathrm{O}$ animal é um ser acaparado, ou seja, visa o que serve imediatamente às suas pulsões, absorvendo do seu meio apenas o que ele investiu de sinal vital (BIMBENET, 2014, p. 97-98). É o que Merleau-Ponty (2006, p. 245) defendeu de um "campo elétrico", isto é, um princípio regulador que mantém uma relação entre as partes e o todo, mesmo este "todo" limitando-se ao seu entorno, no caso animal. Esta limitação impede que ele idealize o mundo na sua totalidade e novas formas de viver. Bimbenet (2014, p. 39-42; 82-83), em especial, caracteriza a idealização da vida e a transcendência do mundo, ao invés do limite do ambiente, o essencial de nossa humanidade.

O que Bimbenet defende como uma postura fenomenológica para falar da experiência animal é, antes de tudo, suprimi-la de mundo - no sentido de totalidade, que só ao homem é possível -, para que evitemos um antropomorfismo quando nos relacionarmos a ela.

Em Scheler (2003, p. 40), a experiência animal apresenta uma descontinuidade do agir por faltar a força espiritual, que é exclusiva do homem. Esta afirmação já está carregada de um antropomorfismo tal qual o denominamos acima. A diferenciação encontrada na filosofia scheleriana entre homem e animal está baseada em uma perspectiva humana, ou seja, Scheler parte do mundo humano e, por conseguinte, de sua visão estrita. Com esta "contaminação antropomórfica" tendemos a compreender o animal a uma visão empobrecida de sua própria conduta. Isto é, enxergamo-lo como um ser limitado por faltar à sua estrutura uma dimensão ricamente empreendedora como no homem, visto que nos tornamos referência. No entanto, é 
preciso analisar o mundo animal a partir de sua própria ótica, de sua vivência e de sua forma de se relacionar com seu meio. Para tanto, é necessário que excluamos desta narrativa qualquer alusão ao mundo humano.

A inteligência prática que Scheler atribui aos animais está vinculada a uma espécie de "concessão" da natureza. Neste caso, a inteligência se explica pela forma natural própria de cada animal, e, não, como sua forma de viver. É a este tipo de concessão que Bimbenet quer se opor, trazendo para a discussão da animalidade não um determinismo comportamental, mas a forma de como a animalidade se relaciona com seu meio, na aplicação de um sinal vital, etc. Esta concessão está no fato de a natureza dispor de um "corretivo" (SCHELER, 2003, p. 2829) para os seus riscos. Tal corretivo, para este autor, seria a inteligência prática, a qual ainda é "organicamente vinculada" (SCHELER, 2003, p. 29). No entanto, admitir este fato "extraanimal" é negligenciar a existência de uma subjetividade no processo de vivência da animalidade. $\mathrm{O}$ animal não se restringe a reações impulsivas, mas também existe uma "referência ao futuro" (MERLEAU-PONTY, 2006, p. 235). Isso quer dizer que há um processo pelo qual o animal se dispõe de uma conjuntura que lhe deixa no estado "daquilo que ele pode fazer" (MERLEAU-PONTY, 2006, p. 235). Não se deve interpretar esta referência ao futuro como uma idealização, mas apenas como uma adaptação frente às instâncias de seu ambiente, o que requer a manutenção de um estado propício à vida. Aqui, vê-se que este estado é a efetivação de uma forma de vida não mais ekstática, mas um modo que, mesmo no limite de seu ambiente, investe as coisas de um sinal para suas próprias atitudes. Com isso, o animal está sempre disposto àquilo que ele pode executar.

O reconhecimento, em Scheler, de uma inteligência prática e do aparecimento de uma forma psíquica animal não exclui o fato de ele enxergar nesses dois fatos apenas um súbito e determinante acontecimento da natureza. É claro que não podemos deixar de enfatizar a raiz natural de tais eventos. Entretanto, o comportamento animal é uma via pela qual este se preserva, de maneira não apenas reativa, mas investido de uma significação que ele mesmo ali colocou. Se houve um sinal é porque o meio no qual vive tem um caráter significativo. E este caráter não se reduz a um mero espetáculo natural "coisificado": é significativo porque o existe para um olhar. Portanto, o olhar animal visa seu meio e as coisas revestidas do Merkmal, sempre na iminência do agir e sempre na "preocupação" de se manter disposto às situações.

Scheler (2003, p. 31), como já frisamos, reconhece "ações autenticamente inteligentes" nos animais. Embora isso pareça ser uma concessão da natureza, este filósofo 
alemão admite o estado inteligente que ultrapassa o mero impulso. No entanto, o autor não demonstra a vida vivida enquanto animalidade. Sua análise parece versar sobre um vitalismo, ou seja, uma causalidade mecânica, e, com isso, uma visão em terceira pessoa. Há, na análise scheleriana, uma espécie de objetividade da vida, isto é, ações determinantes que delimitam o campo de ação do animal enquanto vivente. Além disso, a instauração de instinto, inteligência, pulsão, de antemão, permite Scheler fazer apenas uma pobre narrativa da experiência animal. Isso porque seu narrar já nasce com a concepção de inteligência prática e sua serventia, quando a denomina de "corretiva". Assim, diferentemente da noção de que o animal é um ser que se comporta "ekstaticamente" (SCHELER, 2003, p. 39), ele faz de seu meio em que está envolto sua própria sombra, ou seja, retira do mundo a condição de exercer suas ações vitais e práticas. O viver ekstático, para o alemão, só não corresponde ao esquema corpóreo do animal, uma vez que este se locomove espontaneamente no espaço, canalizando suas impulsões (SCHELER, 2003, p. 38-39).

Diante destes impasses, mas também de pontos de convergência entre a postura de Scheler e Bimbenet - quando falamos de inteligência prática, por exemplo, mesmo com suas nuanças -, podemos resumir o modo-de-ser animal, dentro de um método fenomenológico, como se segue.

Para nos colocarmos no lugar do animal é preciso partir de uma objetivação de seu "debate" com o mundo. Esta objetivação se dá de uma perspectiva nossa. No entanto, nossa visada para com o animal não deve ser do tipo behaviorista, o qual examina o comportamento para enquadrá-lo em uma espécie de determinismo natural, que especifica cada gesto com um significado. Portanto, embora partamos de uma posição nossa, não o fazemos partindo de nosso modo de ser, mas apenas como referencial de lugar. Dessa forma, como afirma Bimbenet (2014, p. 112), nossa perspectiva deve fornecer a referência do ponto de vista do animal, de onde ele percebe, no sentido estritamente espacial. Em outros termos, como não podemos experienciar em primeira pessoa a vida própria de um animal, devemos considerar o ponto de vista objetivo de seu modo-de-ser. Para isso, o entrecruzamento do objetivo com o subjetivo faz-se necessário, tendo em vista que a objetividade do comportamento animal não oblitera a "interioridade a si mesma da vida" (BIMBENET, 2014, p. 111). Dessa forma, precisamos imaginar, primeiramente, de onde ele percebe; depois, podemos imaginar outros pontos de vista estritamente espaciais. A partir da referência do animal, e com estes pontos direcionais, devemos compreender as motivações que o levam a direcionar suas ações a 
determinado "objetivo". Tais motivações são "espacial, biológica e cognitiva sobre o mundo." (BIMBENET, 2014, p. 112).

Com esse perspectivismo exposto, ou seja, a partir da referência própria do animal aos seus pontos de direcionamento, podemos afirmar que, além das motivações biológicas, há sempre um direcionamento que visa um mundo particular do animal: o "ver cognitivo". Por meio da perspectiva é que se pode associar à objetividade do mundo a subjetividade daquele que vive e que se locomove livremente. Isto é, mesmo que percebamos os modos objetivos dos pontos de vistas é preciso que entendamos a forma que a animalidade se articula no seu mundo, através de sua subjetividade peculiar. É, portanto, no “debate" entre animal e o seu mundo visado, como frisa Bimbenet, que devemos dar à animalidade sua particularidade intrínseca, sem contaminá-la, assim, com algum antropomorfismo de visão de terceira pessoa. Nesta via, o animal não vive objetivamente, mas em um constante embate entre o que visa e aquilo que está posto diante de si, pois só com sua subjetividade para dar contornos vitais e de "interesse" próprio à sua conduta. Dessa forma, podemos afirmar, juntamente com MerleauPonty (2006, p. 246), que o comportamento não é anterior nem posterior ao organismo, mas correlato de uma vivência que requer sempre uma "invenção" frente ao mundo.

\section{Do animal ao homem: a "catapulta" scheleriana}

Scheler dá um salto monumental ao sair do "nada" animal ao "tudo" humano. A espiritualização do homem é um fenômeno que vem romper toda uma trajetória evolucionária do ser-no-mundo. Isso fica explícito quando ele afirma que o novo estágio da vida do homem - enquanto ser espiritual - não deve ser reduzido à "evolução natural da vida" (SCHELER, 2003, p. 35). Esta não redução evolucionária dá lugar, por assim dizer, à redução ao fundamento supremo das coisas, o que Scheler defende como o princípio divino.

A antropologia filosófica scheleriana atribui à essência do homem sua origem metafísica (SCHELER, 1986, p. 73). Esta origem, embora seja relacionada à divindade, não nos diz nada sobre sua "construção". Scheler parte do dogma divino e o estende ao ser humano, afirmando que este é parte, em menor grau, de Deus (SCHELER, 2003, p. 85-90). Por ser parte da divindade, o homem está em constante tentativa de autodeificação. Esta postura dogmática e puramente metafísica, no sentido de que a vivência do homem está subordinada a uma determinação extra-humana, faz com que uma antropologia filosófica sucumba-se numa teologia antropológica. Em outras palavras, o homem torna-se, nestas 
circunstâncias, apenas aquilo que se entende como divino, uma vez que ele é parte do princípio supremo. Com isso, o agir humano é, na verdade, uma autodivinização que parte de uma ideia teocêntrica e que exclui a realidade dos afetos humanos no seio do mundo. É claro que, mesmo divinizando o homem, Scheler não nega esta afetividade com o mundo. Contudo, o que queremos afirmar aqui é que o ser-no-mundo, neste sentido, está acorrentado a atributos estritamente divinos. Suas ações, dessa forma, são determinadas pelo modo "deificante" de ser, e, não, pelas experiências no mundo vivido (Umwelt).

Nesse processo de divinização humana, o homem, para Scheler, é um "relativo asceta da vida" (SCHELER, 1986, p. 37). Este ascetismo se dá em virtude da emancipação do homem das características animais, tais como: instinto, necessidades, determinação pelos estados internos do organismo, etc. O homem é, então, um ser superior a todas as formas basilares de toda a vida. Ele se opõe à própria vida no homem (SCHELER, 2003, p. 35). Isso significa que o ser humano supera - ou pode superar - as bases naturais da existência. Isto é, a ação dos animais, que se restringem ao limite seguro do seu meio, é ultrapassada pelo espírito no homem. Ter espírito, portanto, é a junção da razão mais atos volitivos mais emoção e mais intuição dos fenômenos originários e essenciais. Este "acoplamento" de características, segundo a filosofia scheleriana, faz com que o homem transcenda o mundo e o torne um objeto. O comportamento humano, com isso, por mérito espiritual, é o puro modo de ser representacional e intuitivo; além de inibir livremente os impulsos motores - relacionando àquilo ao qual denominamos um pouco mais acima de "bases naturais" - e valorar as coisas. Dessa forma, o espírito abre o mundo ao homem.

$\mathrm{O}$ afastamento do mundano, por meio de um recurso espiritual, denuncia o ascetismo defendido por Scheler, ascetismo tal que não reconhece a importância da vivência do ser-nomundo humano, enquanto situado na mundaneidade. Para este distanciamento, Scheler lança mão do ato de Ideação. Este ato se refere ao apriorismo, ou seja, é conhecendo as coisas pela sua essência - para além de sua existência - que o espírito no homem se manifesta em uma de suas peculiares características. O conhecimento a priori das coisas é unicamente humano. Mesmo que conheçamos e extraiamos a essencialidade de algo a partir de um exemplo, de um primeiro contato com a coisa em algum momento da vida, a essência daquilo conhecido vale para todas as outras coisas que estejam sobre a mesma fundação. Esta é a cisão à qual Scheler se refere ao defender que apenas o homem é capaz de cindir existência de essência (SCHELER, 2003, p. 49). Essa dissensão só é possível pelo ato de idear, que apreende a cada 
vez as qualidades essenciais da coisa, porquanto esta está sobre os ditames do exemplo de mesma região essencial.

$\mathrm{Na}$ antropologia scheleriana, o homem emerge no mundo dotado de suas dimensões puras e que suas intuições precedem as sensações externas. Isso se deve ao fato de o ser humano fazer parte do "fundamento ontológico mais supremo" (SCHELER, 2003, p. 45). Esta concepção faz com que o autor afirme que o homem faz do mundo um objeto, uma vez que, as intuições de espaço e tempo sendo inatas, o espírito reconhece o mundo e suas dimensões já de antemão.

A separação homem-mundo é um "movimento de pureza". O homem não é mais resultado de uma evolução vital, mas concedido tal como é pela sua origem divina. O enraizamento em Deus e forma de vida superior aos demais seres vivos negligenciam a vida vivida do homem, embora Scheler admita o conhecimento essencial por meio de exemplos, ou seja, de contato com as coisas existentes. No entanto, a essência tirada do objeto é uma disposição espiritual, através do que está impresso como sendo parte de um ser elevado. Com isso, o que fica como indagação é: por que só o homem apresenta as funções divinas e a participação em seu fundamento?

Além de Scheler não apresentar justificativas para isso, ele também não explica o rompimento da animalidade para a humanidade. Mesmo defendendo a origem divina do homem e, portanto, sua humanidade, o autor deveria expor a "reviravolta" que marca a mudança do animal para o homem; e por que este último possui o bônus da deificação. Podese objetar aqui que não há necessidade de abordar tal rompimento porque Scheler não assume uma narrativa evolucionária. Se aceitarmos essa objeção, ainda assim o projeto antropológico deste filósofo se obceca, visto que se parte da forma final em que nos encontramos para explicar a existência.

Uma antropologia se ergue ao ser capaz de narrar a gênese das variadas experiências, ações e comportamento humanos. No caso scheleriano, estes três fatos, no mínimo, já são explicados em sua finalidade, ou seja, Scheler parte do homem tal qual se encontra agora. Nesta perspectiva, a antropologia de Scheler, como a encontramos em sua obra, não nos possibilita explicar a experiência vivida humana sem contaminá-la de um determinismo supramundano ou extra-humano. Por exemplo, o caso das "meninas-lobo", Amala e Kamala duas meninas encontradas, em 1920, numa caverna vivendo com os lobos -, não pode ser entendido por esta pretensa filosofia antropológica. As duas meninas tinham hábitos e comportamento de lobos, denunciando que suas experiências vividas prevaleciam no processo 
de conhecimento, sociabilidade e convenções. Se as faculdades humanas fossem participantes de um fundamento supremo, ao qual se assemelhassem, não entenderíamos como as meninaslobo se comportavam como animais, e que de humano só possuíam sua estrutura fisiológica. Se esta tese de Scheler fosse verdadeira, as meninas, mesmo se criando entre animais, se diferenciariam destes em virtude de seu funcionamento divinizador. $\mathrm{O}$ exemplo da vivência na matilha não teria peso nos hábitos das crianças, tendo em vista que as intuições a priori e a autoconsciência, que são características propriamente espirituais (SCHELER, 2003, p. 39), não sofreriam mácula.

Diante dessas dificuldades da filosofia de Scheler, devemos entender que o processo hominizante precisa ser tratado levando em conta a vivência humana, sua ex-sistência, à la Heidegger (2010), ou seja, estar-jogado-no-mundo e, portanto, fazer deste mundo o seu solo de sustentação.

\section{Diferenças mundanas dos animais e do homem}

Como já frisamos na Introdução, não pretendemos expor o processo pelo qual o homem se tornou o que é deixando a animalidade para trás. Queremos, neste tópico, mostrar a fraqueza de Scheler ao elaborar sua antropologia.

Merleau-Ponty (2006, p. 271-323), ao analisar o comportamento animal realizado por Uexküll, afirma que o animal - mesmo nós já tendo afirmado que ele age no limite de seu mundo geográfico - possui seu mundo circundante/vivido. Por que precisamos salientar isso? Porque, se excluirmos o Umwelt para os animais, corremos o risco de colocá-los sob os ditames de um automatismo. Portanto, o limite de seu mundo, mesmo estando restringido àquilo que o animal percebe, está envolvido por um sinal vital, do qual já falamos. Este sinal só é possível a uma subjetividade que retira do seu meio um tipo de forma de vida. Embora o animal seja pobre de mundo, como quer Heidegger (2011), não podemos dizer que ele não tenha mundo. Ele apenas não o totaliza para além do percebido, como no caso humano. Esta orientação comportamental do animal para um Umwelt existe mesmo antes da consciência. $\mathrm{O}$ animal age pelas estimulações que o levam à disposição de receber e tratar os sinais do seu meio (MERLEAU-PONTY, 2006, p. 271-272), extrapolando a sua condição unicamente fisiológica. Com isso, a consciência, tal qual enxergamos no homem, passa a ser apenas uma forma de comportamento. 
O mundo circundante do animal, apesar da "limitrofia", nos coloca de frente ao paradoxo scheleriano que, embora Scheler admita que o animal apresenta mais que o instinto, o homem é superior e sublime (SCHELER, 1986, p. 37). É claro que o homem não é mais um puro animal. Entretanto, este último possui funções, em menor grau, que são germes de nossas funções desenvolvidas e complexas. Se não houvesse um processo adaptativo e, por isso, evolutivo, não seria possível compreendermos como os animais inferiores são mais limitados que os animais superiores, e, mesmo assim, ainda são animais. Ou seja, o Umwelt “deixa de ser fechamento para ser abertura" (MERLEAU-PONTY, 2006, p. 277) nos animais superiores em oposição aos inferiores. Em outros termos, se a complexidade do homem for atribuída à sua divinização proveniente de seu fundamento, seria preciso atribuir aos animais superiores, senão um princípio supremo, ao menos uma diferenciação em sua origem em relação aos animais inferiores. Diferenciação tal que não passasse pelo crivo da evolução/adaptação, mas um princípio, de certa forma, extramundano, como acontece com o ser humano. Dito isso, por que essa diferenciação, em Scheler, só se atribui ao homem em relação a todos os animais?

Os animais inferiores, segundo Merleau-Ponty (2006, p. 272), têm a característica de parecerem máquinas. Isso porque seus movimentos retratam uma conformidade, uma sequência quase inalienável. A exemplo disso são as águas-vivas mais "primitivas”, uma vez que seus movimentos se exercem a partir de três funções: deslocamento, abertura do tubo digestivo e respiração com água oxigenada. (MERLEAU-PONTY, 2006, p. 272). Estes animais possuem uma constituição que os assegura os movimentos necessários à manutenção da vida, principalmente pela busca de alimentos. O mundo externo, nesse caso, não exerce nenhuma função significativa com poder noemático ao animal, ou seja, o mundo não exerce a recíproca de um mundo prenhe de significado, mas apenas um meio imediato e “assignificativo". Portanto, os animais inferiores são como uma espécie de automatismo, de animal-máquina.

Os animais superiores estabelecem no mundo sua própria forma de vida, sem serem impelidos a agir apenas para manter a vida, fugindo da morte. Isto é, estes animais possuem um mundo, e agem neste mundo em virtude do sinal que investe às coisas ao seu redor. Este Merkmal faz com que eles transbordem o simplismo darwiniano de fuga da morte, a fim apenas de sobrevivência. Para o evolucionismo darwinista, a vida é constantemente ameaçada de morte, levando os animais a estarem sempre fugindo deste fatalismo. Se negarmos este fator único darwiniano, entendemos melhor porque os animais brincam e mantêm relações 
afetivas com seus pares ou com seus donos - no caso de animais domésticos - e até com animais de outras espécies. Isso, visivelmente, não pode ser apenas instinto de sobrevivência. Há, aí, um significado além da "fuga da morte". O mundo circundante destes animais não é mais unicamente a "despensa alimentar", mas a abertura para novos sinais que visam outras formas de relação e de possibilidades.

No homem, vemos a capacidade de idealização e totalização do mundo e de múltiplas formas de vida. Todavia, não podemos imaginar estes novos atributos como uma concessão divina à la Scheler, porque toda forma de se relacionar com o mundo, no homem, mesmo que seja completamente nova em relação aos animais, está intrinsecamente ligada ao seu mundo vivido. Como acontece com os animais superiores, seu modo de "ver" o mundo é mais aperfeiçoado e diferente que nos animais inferiores. A gradação que vemos aqui se refere à experiência vivida de cada animal ou espécie. Com o ser humano não deve ser diferente, uma vez que sua evolução se dá no processo efetivo em seu Umwelt.

O evento completamente novo - o humano - em Scheler é a purificação da espécie humana. O aditivo espiritual nega a raiz animal da qual o homem subleva-se. Nada de mundano constrói a conduta do ser-homem no seio do seu mundo vivido. Com isso, a antropologia scheleriana parece se assemelhar, em certa medida, ao intelectualismo cartesiano. Isso parece claro quando Scheler (2003, p. 47) dá um exemplo de Ideação usando a dor. Nisso, ele afirma que sentir a dor leva o homem a abstrair do aqui e agora e pensar a dor em si mesma, em sua essência. O exemplo atual da dor é apenas um espetáculo particular daquilo que possui uma essência muito anterior e estranha ao homem. A correlação com Descartes que mencionamos está no exemplo da cera por este filósofo, o qual defende uma essência de cera anterior e diferente da aparência com que ela se nos apresenta, uma vez que pode aparecer de várias formas distintas sem deixar de ser o que é (Cf. Meditações Metafísicas, Meditação segunda). No entanto, como defende Bimbenet (2014, p. 34), a Idealidade não é separada do mundo, mas é aquilo resultado da vivência com o fenômeno, valendo para toda consciência possível. Ainda como Merleau-Ponty (2004, p. 21) afirma, uma qualidade só é compreendida por nós através do debate que ela estabelece entre o sujeito encarnado que somos e o exterior. Sendo assim, o "idear" é uma atividade-passividade, que só tem sua razão de ser por meio da vivência própria do homem em seu mundo vivido - visando as coisas e as coisas imprimindo um sinal para investi-las. Nesta perspectiva, o homem, assim como os animais, não age no mundo de forma vertical e de cima para baixo; mas horizontalmente e numa mutualidade tal que muda o mundo e o mundo o muda. 
O que podemos concluir com estas diferenciações de animais inferiores para animais superiores e para o homem?

Devemos entender que há uma melodia recíproca entre ser e Umwelt. Esta melodia se configura pelo debate que o animal - e, é claro, o homem - realiza com seu mundo. Nos animais inferiores, os "animais-máquinas", suas ações são promovidas por receptores sensoriais que implicam em reações motoras (MERLEAU-PONTY, 2006, p. 279), como no caso da água-viva e do polvo. Estes animais, por exemplo, agem de forma a se alimentar e a se defender de predadores. Nos animais superiores há uma réplica do mundo para si, isto é, estes animais "conquistam" o mundo externo e o fazem como seu mundo próprio. Isso se deve ao fato de como seus órgãos sensoriais são feitos e de como, através desta sensibilidade, eles reagem ao meio ambiente. Às percepções adicionam-se as condutas, o que faz com que os objetos, percebidos pelos animais, sejam cobertos de uma significação. Esta significação não é a ação de uma "consciência supra" que desce ao mundo, mas uma qualidade que é exercida pela bilateralidade entre animal e mundo. Em outras palavras, o animal se produz também a partir da produção de um meio (Merleau-Ponty, 2006, p. 281), ou seja, ao mundo físico aparece um campo que dele se difere, com suas estruturas específicas que faz com que o animal se relacione e imprima significados novos àquilo por intermédio de sua conjuntura própria. Nos humanos, o debate entre a sua Natureza e a Natureza fora de si é o que promove a humanidade, que procura o nexus entre uma e outra (MERLEAU-PONTY, 2006, p. 332), da perspectiva que assumimos.

Nossa humanidade, portanto, é uma outra/nova maneira de ser corpo, de perceber a nossa volta a partir da constituição mesma que somos, de nosso esquema corporal. Isso não se deve a uma substância que paira sobre nós, mas àquilo que Merleau-Ponty (2006, p. 336) chama de interser, ou seja, de uma relação mútua entre o ser que somos e o ser da natureza exterior; uma imbricação, o um-no-outro (Ineinander). Isso já ocorre, em menor grau, como expusemos mais acima, com os animais superiores, isto é, eles investem de significado o que se difere de sua forma física, para manter uma relação de proximidade e de "pertencimento"; e isso não deixa de ser um nexus entre uma Natureza e outra.

Com estas relações e nuanças expostas, compreendemos que as vidas animal e humana se distinguem em essência, mas não em sua raiz. Em outras palavras, elas possuem formas próprias e peculiares a cada espécie, mas sem deixar de ser originadas e vividas a partir de uma relação imanente com seu mundo. Portanto, o que faltou em Scheler foi "humanizar o homem" por meio de sua experiência vivida, experiência tal que formou todo o seu aparato 
cognitivo, em vez de este aparato existir predispostamente no advento do fenômeno humano como "co-realização da ideia da divindade" (SCHELER, 1986, p. 38).

\section{Conclusão}

A animalidade exerce sua função na correlação entre sua "arquitetura" própria e as formas com que o mundo aparece. Também o é assim no homem. Da animalidade, mantemos essa forma intrínseca de se relacionar com o que está à nossa volta, com o adendo de totalizar e idealizar toda uma vida e todo um projeto de viver.

O finalismo de Scheler, ou seja, pressupor o modelo de homem atual em um itinerário teleológico, exclui uma narrativa evolutiva e de construção gradativa da humanidade em função de um fim que já propriamente humano. Se levarmos em consideração que nossa humanidade é a co-realização com Deus, afirmamos que a finalidade humana é a mimetização divina, como o próprio Scheler (1986), de acordo com o que mostramos, afirma. Nesse contexto, o aparecimento humano já está irradiado com sua tarefa final, que é divinizar-se. Os animais, com isso, diferenciam-se não apenas em sua essência com o homem, mas em sua origem. Fica, portanto, a sensação de uma ruptura abissal entre estes dois seres vivos.

O que Bimbenet (2014, p. 53-54) nos diz é que ao homem não é "prometida" a inteligência - ou a consciência -, mas a possuímos porque nosso cérebro "aproveitou" todas as mudanças físicas evolutivas para se expandir. A caixa craniana se abriu para a verticalização do tronco e, por isso, a massa cefálica se prontificou em preenchê-la. Portanto, com o cérebro bem maior que os animais, o homem despertou novas formas de tecer sua vivência no seio do mundo. Com isso, a consciência é a própria efetivação da experiência humana, fazendo um paralelo com o que Merleau-Ponty (2011, p. 503) defende em relação à percepção. Assim, a consciência não é anterior ao experienciar o mundo, mas coetânea.

Qual é, então, a relação do que afirmamos com as meninas-lobo? A experiência vivida das crianças estava restringida a um único formato: o animal. Em seu desenvolvimento, a humanidade não se manifestou pelo fato de a vivência estar condicionada a uma cultura nãohumana. Isso mostra que o mundo das crianças era o mesmo mundo dos lobos, e que suas funções estavam ligadas às práticas de uma determinada sociedade. A limitação cognitiva das meninas, além das motoras, denuncia que aquele sinal vital investido no mundo só extraía o que os exemplos animais permitiam, mostrando, com isso, que o viver está ligado inerentemente ao grau de significação que atribuímos ao mundo vivido. 
Nem a possibilidade de defender a antropologia scheleriana, afirmando que o espírito e suas faculdades existem primeiramente em potência e só com o seu "uso" é que o homem pode se humanizar, é viável. Isso porque Scheler (2003, p. 36-46) é enfático ao dizer que o ser espiritual pode "apreender em princípio por ele mesmo" a essência das coisas. Essa afirmação não permite a conjetura de uma vida espiritual apenas em potência, mas, ao contrário, admite uma atualidade constante de um ser sublime. Assim, se apenas por força do espírito (SCHELER, 2003, p. 39) o homem consegue se autoconscientizar, a fim de conhecer a si mesmo, podemos concluir que as meninas-lobo eram desprovidas deste princípio supremo, uma vez que uma delas viveu por mais oito anos e os avanços "humanizantes" foram ínfimos - faleceu com aproximadamente cinquenta palavras em seu vocabulário. Se não eram desprovidas de espírito, qual o motivo pelo qual elas não desenvolveram sua humanidade mesmo entre os lobos ou mesmo depois de serem levadas ao orfanato? Ainda se houvesse tido tempo de humanizá-las, teria sido pelo processo cultural e de aprendizado, corroborando para o que defendemos que animalidade e humanidade são qualidades e estruturas vivenciais. Novamente: se as meninas tivessem vivido o tempo necessário para desenvolverem sua humanidade, o fato de elas, em um momento, terem vivido como animais e, em seguida, como humanos, nos mostra que, apenas por meio da experiência vivida é que se pode formar modos de vida. Nesse caso, um mesmo humano teria ex-sistido como animal e homem apenas por força de sua vivência. Dentro do campo antropológico, o advento espiritual, numa hipotética defesa da postura scheleriana, não encontraria critério de investigação e, por isso, sucumbir-se-ia. Vemos que atribuir as habilidades humanas a um princípio regulador ou “possibilitador" é problemático, tendo em vista que a experiência vivida do ser perde a importância de caráter indelével.

Em resumo, a exclusão de uma metafísica deste tipo, que obceca o processo hominizante em detrimento de uma concessão extra-humana, é necessária para o estudo da hominização e, portanto, da antropologia, seja filosófica ou não. A alusão à divindade, neste caso, faz com que o movimento que deve ser destinado ao homem tome outro caminho: o de um deus fundador. Se assim o for, o trabalho da antropologia filosófica cessa suas pesquisas para dar lugar à teologia, porquanto o homem pode ser explicado pelo fundamento divino. 


\section{Referências}

BIMBENET, Étienne. O animal que não sou mais. Tradução de Maurício José D’Escragnolle Cardoso. Paraná: Editora da UFPR, 2014.

DESCARTES, René. Meditações Metafísicas. Tradução de Maria Ermantina de Almeida Prado Galvão. $2^{a}$ ed. São Paulo: Martins Fontes, 2005. (Coleção Clássicos).

HEIDEGGER, Martin. Carta sobre o Humanismo. Tradução de Rubens Eduardo Frias. $2^{\mathrm{a}}$ edição revista. $1^{\text {a }}$ reimpressão. São Paulo: Centauro, 2010.

HEIDEGGER, Martin. Os conceitos fundamentais da metafísica: mundo-finitude-solidão. Tradução de Marco Antonio Casanova. 2a edição. Rio de Janeiro: Forense Universitária, 2011.

MERLEAU-PONTY, Maurice. Conversas - 1948. Traduções de Fábio Landa e Eva Landa. São Paulo: Martins Fontes, 2004.

MERLEAU-PONTY, Maurice. Natureza, A. Tradução de Álvaro Cabral. São Paulo: Martins Fontes, 2006.

MERLEAU-PONTY, Maurice. Fenomenologia da Percepção. Tradução de Carlos Alberto Ribeiro de Moura. $4^{\mathrm{a}}$ edição. São Paulo: WMF Martins Fontes, 2011.

SCHELER, Max. Visão Filosófica do Mundo. Tradução de Regina Winberg. São Paulo: Perspectiva, 1986.

SCHELER, Max. Posição do Homem no Cosmos, A. Tradução e apresentação de Marco Antônio Casanova. Rio de Janeiro: Forense Universitária, 2003. 